\title{
Teenager with Rosette-Forming Glioneural Tumour of the Fourth Ventricle: Case Study of a Rare Tumour
}

\author{
Daina Apskalne*, Karlis Bicans**, Dmitrijs Gavrilins* \\ *Riga Eastern Clinical University Hospital and Riga Stradins University, Latvia \\ **Riga Eastern Clinical University Hospital
}

\begin{abstract}
Summary
We report the case of uncommon rare tumour of the fourth ventricle in young person. This diagnosis is included to WHO classification only in 2007. Tumour was identified by the MR imaging, later on surgically removed with post-operative MRI control scan. Diagnosisrosette-forming tumour of the fourth ventricle- was confirmed both morphologically and immunohistochemically.

Key words: rosette - forming tumour of the fourth ventricle; diagnostics.
\end{abstract}

\section{AIM OF THE DEMONSTRATION}

The aim of the article is to demonstrate rare diagnosis case, which was confirmed for the first time only in 2007, its options of management and diagnostics in Latvia in order to add our experience to the published data.

\section{CASE REPORT}

12 y.o. female teenager admitted to the Department of Neurosurgery, Riga Children's Clinical University Hospital, complaining of recurrent headache during the past 8 months. Nausea and recurrent vomiting occurred in past month before admission. Patient showed no neurological focal signs when admitted. After the following MRI assessment the tumour of the $4^{\text {th }}$ ventricle with secondary contrast enhancement was discovered (Fig.1). For the further surgery girl was transferred to the Department of Neurosurgery, Riga Eastern Hospital, Clinic Gailezers. The operation- subtotal tumour removal was successfully managed. Post-operative period showed no complications, operative wound healed per primam. MRI control assessment followed (Fig.2). Patient was discharged from the hospital without neurological focal signs. Surgical biopsy was morphologically and immunochemically investigated. Diagnosis - Rosette-forming glioneuronal tumour of the 4 th ventricle confirmed.

\section{DISCUSSION}

Rosette-forming glioneuronal tumour of the $4^{\text {th }}$ ventricle (RGNT) has been initially described in scientific literature in 1995 as cerebellar form of dysembryoplastic neuroepithelial tumour (4), but as a nosological entity was characterized by Komori et al (5) in 2002 after study of 11 cases. Till the present time number of cases of morphologically and immunohistochemically confirmed RGNT of the $4^{\text {th }}$ ventricle is only a little more than $20(6,7)$. This relatively small amount of cases can be added by our case, which fully fits with all characteristics of reported classic RGNT.
Analyzing the clinical status of our patient in comparison with reports published we found common complaints of headaches, nausea, vomitus $(2,3)$, followed by visual disturbances, vertigo, ataxia. In our case only complaints of headache, nausea and recurrent vomitus were found out. Based on the experience reported to date, RGNT is more common in young female and teenage females (1), which fits with our case. Common localization of RGNT - the $4^{\text {th }}$ ventricle- was also identified in our case (Fig. 1,2).

After the morphological analysis of our case classic structure of RGNT was found: Tumour formed by neurocytic (Fig. 3) and astroglial (Fig. 4) components $(1,6)$. Neuronal structure formed by typical neurocytic Homer Wright-like rosettes (Fig. 5) and perivascular pseudorosettes (Fig.6).

Immunohistochemical study of RGNT in published reports $(1,3,6)$ as well as in our case showed the immunoreactivity of neurocytic rosettes for synaptophysin (SYN) in granular fashion (Fig. 8) and reactivity of glial components for glial fibrillary acidic protein (GFAP) (Fig. 7).

In the series of Komori et al (5), tumoral MIB-1 indices ranged from $0,35 \%-3,07 \%$ (mean, $1,58 \%$ ). In our case proliferative activity of $2 \%$ was found (Fig. 9).

In our case grade 1 of tumour anaplasia can be formulated, which in combination with almost total resection (Fig. 2) and low index of proliferation has favorable prognosis and long recurrence-free period.

\section{Conflict of interest: None}

\section{REFERENCES}

1. Hainfellner JA, Scheithauer BW, Giangaspero F, Rosenblum MK. Rosette - forming glioneuronal tumor of the 4 th ventricle ( RGNT ). In: World Health Organization classification of tumors of the central nervous system // JARC: Lyon, 2007; 32: $115-116$ 
2. Johnson M, Pace J, Burroughs JF. Fourth ventricle rosette - forming glioneuronal tumor. Case report // J Neurosurg, 2006; 105:129 - 131

3. Jacques TS, Eldridge C, Patel A, Saleem NM, Powell M, Kitchen ND, Thom M, Revesz T. Mixed glioneuronal tumor of the fourth ventricle with prominent rosette formation // Neuropathol Appl Neurobiol, 2006; 32:217-220

4. Kuchelmeister K, Demirel T, Schlorer E, Bergmann M, Gullotta F. Dysembryoplastic neuroepithelial tumor of the cerebellum // Acta Neuropathol (Berl), $1995 ; 89: 385-390$

5. Komori T, Scheithauer BW, Hirose T. A rosette forming glioneuronal tumor of the fourth ventricle: infratentorial form of dysembryoplastic neuroepithelial tumor? // Am J Surg Pathol, 2002; $26: 582-591$

6. Marc K Rosenblum. The 2007 WHO classification of nervous system tumors : neurly recognized members of the mixed glioneuronal group // J Brain Pathol, 2007; 17: $308-313$

7. Pimentel J, Resende M, Vaz A, Reis A, Campos A, Carvalho $\mathrm{H}$, Honavar M. Rosette - forming glioneuronal tumor: pathology case report // Neurosurgery, 2008; 62: 1162-1163

\section{Address:}

Daina Apskalne

Dept. of Neurosurgery,

Riga Eastern Clinical University Hospital

Hipokrata str. 2, Riga, LV - 1038, Latvia

E-mail: daina.apskalne@inbox.lv

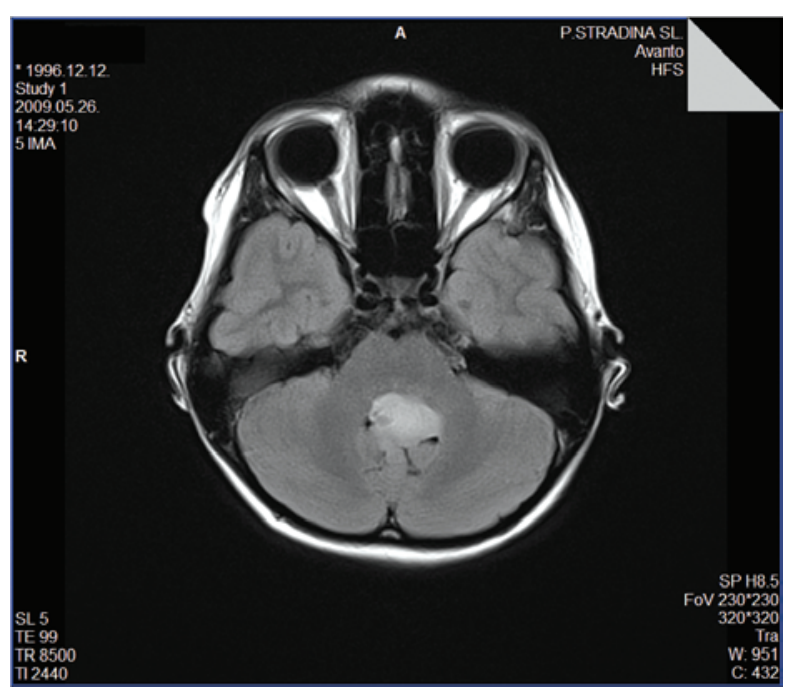

Fig. 1. MRI scan before the operation. Tumour of the 4 th ventricle. Note the contrast enhancement of tumour

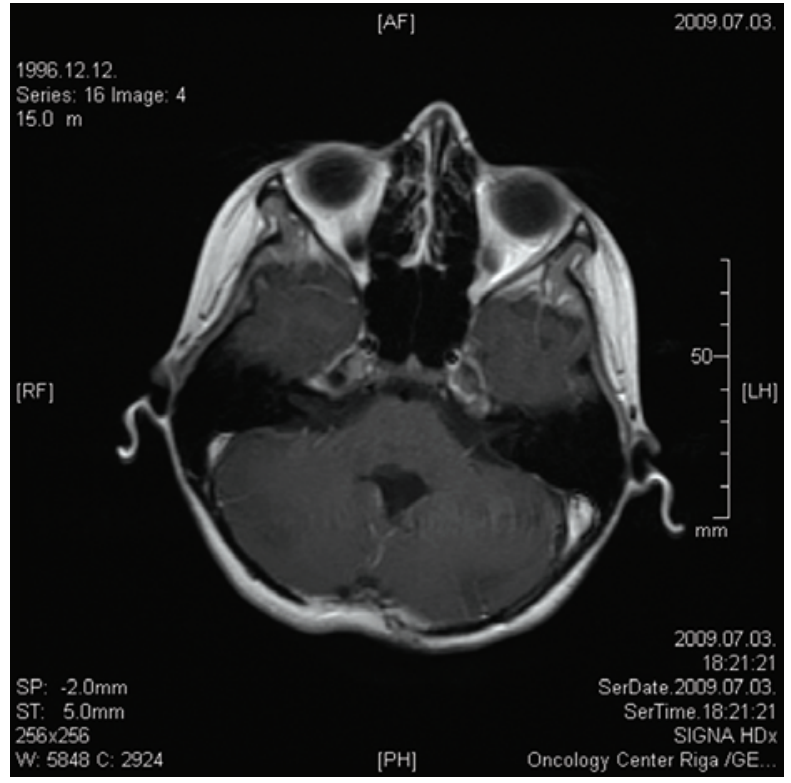

Fig. 2. Post-operative control MRI scan. Status after subtotal resection. Minimal residual tumour tissue without mass effect and disturbance to CSF circulation

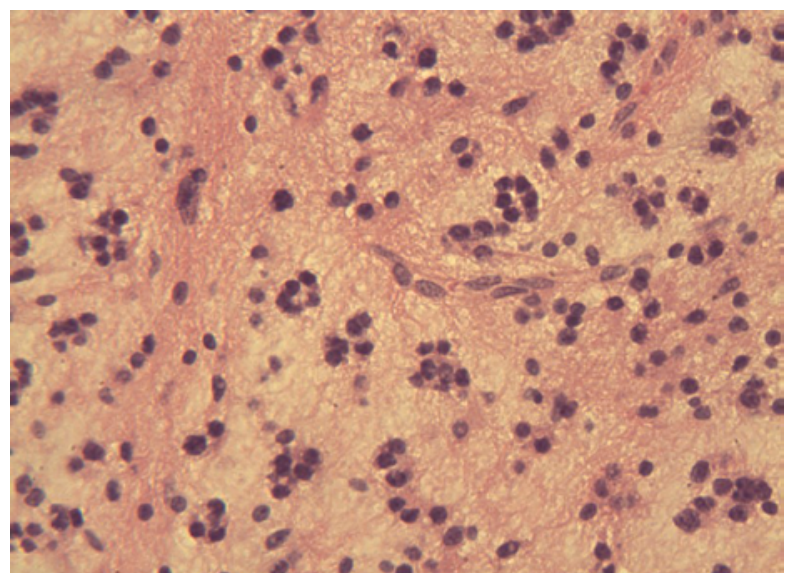

Fig 3. Neurocytic component of RGNT (Obj. 20x, H-E) 


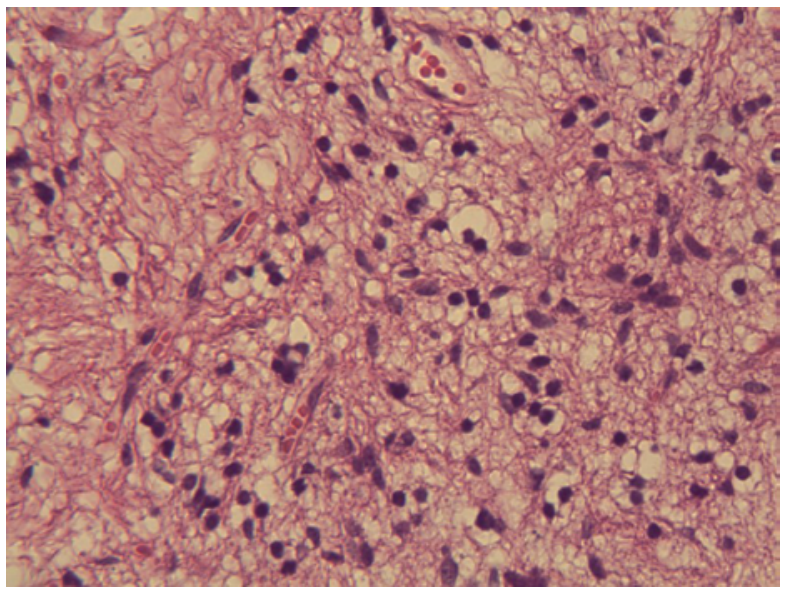

Fig. 4. Astrocytic component of RGNT (Obj. 40x, H-E)

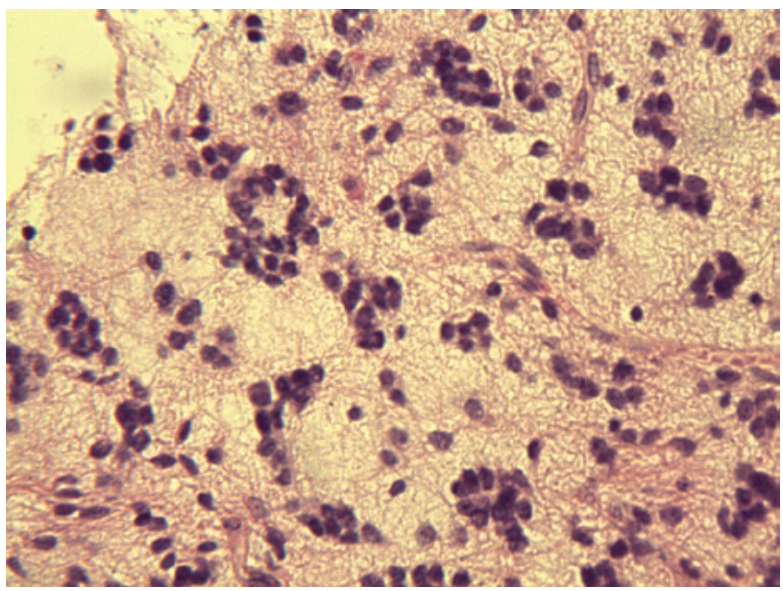

Fig. 5. Histological features of RGNT. True Homer Wright-like rosettes (Obj. 40x, H-E)

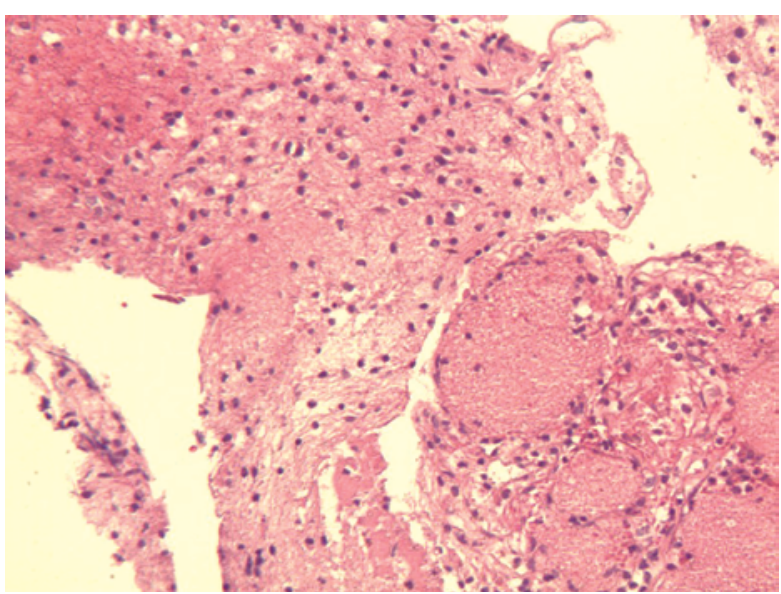

Fig. 6. Histological features of RGNT. Perivascular pseudorosettes (Obj. 40x, H-E)

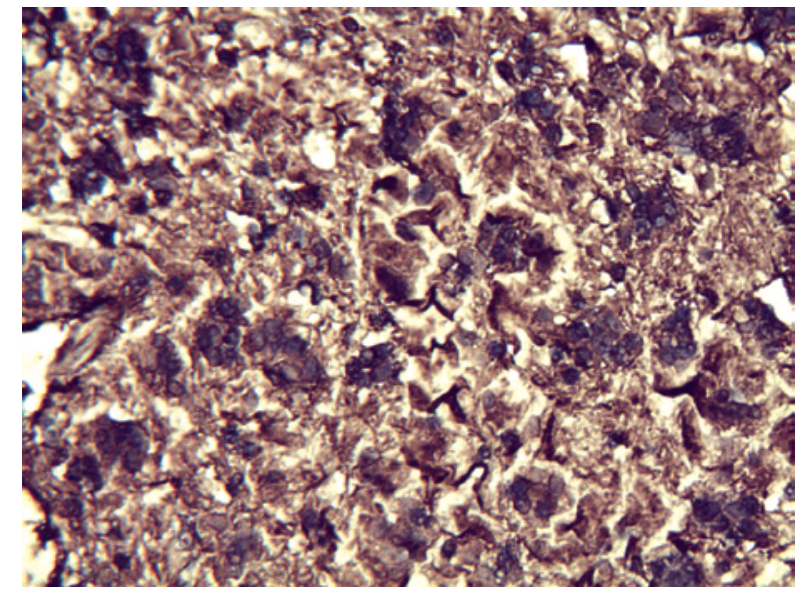

Fig. 7. Immunophenotypic features of RGNT. Glial components of RGNT (Obj. 40x, GFAP)

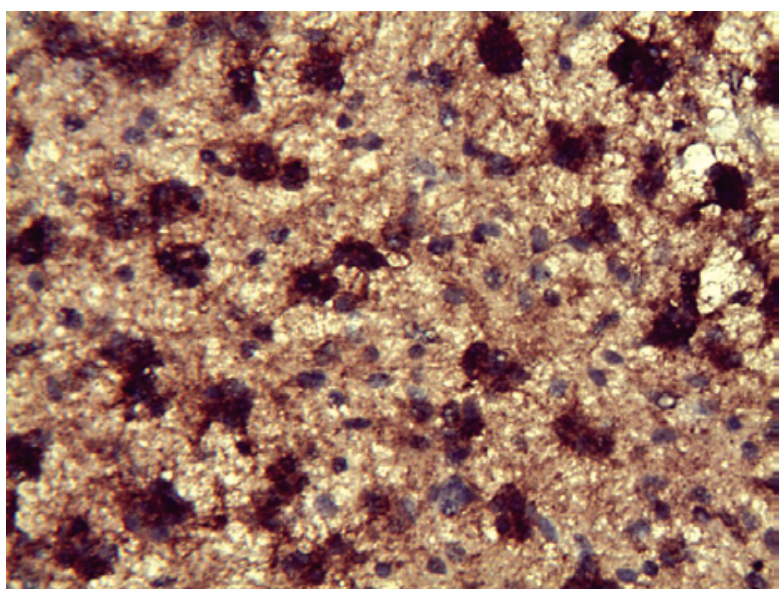

Fig. 8. Immunophenotypic features of RGNT. Rosettes manifest granular synaptophysin Imunnoreactivity (Obk.40x, SYN)

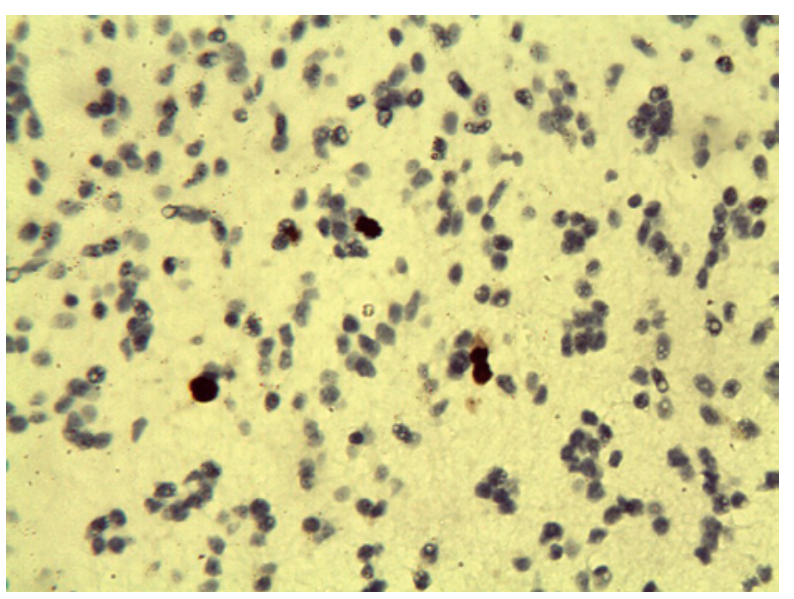

Fig. 9. Ki67/MIB-1 proliferative activity. PI - 2\% 